\title{
Monte y turismo. El turismo forestal en Galicia
}

\author{
Ángel Miramontes Carballada \\ Universidade de Santiago de Compostela-USC. Departamento de Xeografía \\ angel.miramontes@usc.es
}

\section{Resumen}

Este trabajo muestra las principales características del sector turístico en Galicia en la actualidad, para a continuación analizar las peculiaridades de un tipo concreto: el turismo forestal. El objetivo es destacar que el turismo forestal es una actividad con muchas posibilidades de desarrollarse en Galicia y que puede ejercer tanto como elemento dinamizador de ciertas comarcas rurales, como complemento a otras actividades turísticas que ya se desarrollan en el territorio gallego. Para alcanzar este objetivo, se analizan la distribución y las características de los montes y su relación con la distribución territorial de otros tipos de turismo como el turismo rural o el ecoturismo.

Palabras clave: turismo forestal; monte; Galicia.

Resum. Muntanya i turisme. El turisme forestal a Galicia

Aquest treball mostra les característiques principals del sector turístic a Galícia actualment, per analitzar tot seguit les peculiaritats d'una tipologia concreta: el turisme forestal. L'objectiu és destacar que el turisme forestal és una activitat amb moltes possibilitats de desenvolupar-se a Galícia i que pot exercir tant com a dinamitzador de certes comarques rurals, com a complement a altres activitats turístiques que ja es desenvolupen al territori gallec. Per assolir aquest objectiu, s'analitzen la distribució i les característiques de les muntanyes i la seva relació amb la distribució territorial d'altres tipus de turisme com el turisme rural o l'ecoturisme.

Paraules clau: turisme forestal; muntanya; Galícia. 
Résumé. Montagne et tourisme. Tourisme de forêt en Galice

Ce document présente les principales caractéristiques du secteur du tourisme en Galice aujourd'hui et analyse les particularités d'un type spécifique: le tourisme de forêt. L'objectif est de mettre en évidence le fait que le tourisme de forêt est une activité avec de nombreuses possibilités de se développer en Galice et qui peut agir à la fois comme catalyseur pour certaines régions rurales et comme complément pour d'autres activités touristiques déjà développées en Galice. Pour atteindre cet objectif, l'article analyse aussi la répartition et les caractéristiques des forêts et leur rapport avec la distribution territoriale des autres types de tourisme tels que le tourisme rural ou l'écotourisme.

Mots-clés: tourisme de forêt; montagne; Galice.

\section{Abstract. Forests and tourism: Forest tourism in Galicia}

This paper examines the main characteristics of the tourism sector in Galicia today and analyzes the special features of a particular type of tourism: forest tourism. The aim is to highlight that forest tourism is an activity which affords many opportunities for development in Galicia and can function as both a catalyst for certain rural areas and a complement to other tourism activities that have already been developed in Galicia. To achieve this objective, the distribution and characteristics of forests and their relation to the territorial distribution of other types of tourism, such as rural tourism or ecotourism, are analyzed.

Keywords: forest tourism; forests; Galicia.

\section{Sumario}

1. Introducción 4. Los usos y los valores recreativos

2. Características generales de un tipo del monte de ecoturismo: el turismo forestal

5. Conclusiones

3. El monte gallego como Referencias bibliográficas recurso turístico

\section{Introducción}

El turismo forma parte de una de las actividades socioeconómicas sobre las que se asienta la estructura económica de muchos países. Concretamente, España se encuentra entre los primeros países receptores de turismo a escala internacional, siendo esta actividad la que permitió el desarrollo de ciertos territorios y, parcialmente, la economía de España (Cals, Capellà y Vaque, 1995; Besteiro, 1997; Vega, 1997; Buendía y Colino, 2001; Rodríguez y Martínez, 2009).

Nuestro país siempre se caracterizó por ser un espacio receptor de turistas que demandaban el turismo de sol y playa concentrándose principalmente en los archipiélagos (las Islas Canarias y las Islas Baleares) y en el espacio mediterráneo. En la actualidad, este tipo de turismo sigue siendo fundamental dentro de la economía española; sin embargo, están surgiendo otros tipos de turismo bastante consolidados como el turismo cultural, de congresos, urbano o natural 
y, cómo no, el turismo forestal, que cada vez tienen mayor significación en diferentes territorios.

Desde la última década del siglo xx hasta la actualidad, el turismo en Galicia ha tenido una evolución muy positiva, llegando a constituirse como el eje económico de muchas comarcas de Galicia gracias al elevado ritmo de crecimiento de la demanda y a pesar de la menor progresión que tuvo la oferta. Incluso desde la Administración de Galicia se ha definido el turismo como el verdadero sostén de la economía gallega en los primeros años de la crisis económica que se mantiene en la actualidad. Sin embargo, y a pesar de la insustituible significación que tuvo el turismo en el desarrollo socioeconómico de muchos territorios de Galicia, aún mantiene graves problemas que limitan que alcance su verdadero valor como puede ser la estacionalidad. Por lo tanto, la creación y la dinamización de una mayor y variada oferta turística es fundamental, y es aquí donde actividades como el turismo forestal pueden jugar un papel muy significativo.

Galicia, gracias a sus características territoriales, naturales y culturales, posee una serie de elementos potencialmente susceptibles de ser aprovechados desde el punto de vista turístico. En los últimos años, el turismo gallego siempre representó más del 10\% del PIB de Galicia y el 10\% del empleo gallego. A modo de ejemplo y según los datos de Exceltur en el 2010 el turismo supuso el 10,6\% del PIB y el 11,5\% del empleo (Exceltur, 2011). Pero desde la Xunta de Galicia pretenden que los valores del turismo aumenten y en febrero del 2014, con la aprobación del Plan Integral de Turismo, plantean pasar de los 3,7 millones de turistas a 4 millones; de 900.000 turistas internacionales a 1 millón; de una ocupación media hotelera del $29,65 \%$ al 33,54\%; de una estancia media de 2,13 noches a 2,5 noches y de un gasto total de los turistas internacionales de 733 millones de euros a 836 millones (Xunta de Galicia, 2014).

Además, la sociedad gallega es consciente de que el turismo aún no consiguió el nivel de desarrollo adecuado según sus peculiaridades territoriales. Pues, aunque Galicia no posee las mismas características climáticas de otras áreas de España, el turismo tradicional de sol y playa está muy presente y se debe cuidar y dinamizar en ciertas comarcas, como son principalmente las Rías Baixas (todo el litoral de la provincia de Pontevedra). Aun así, la verdadera potencialidad turística de Galicia debe dirigirse hacia otras tipologías como el turismo rural, cultural, naturaleza o forestal, pues además de vincularse a la posibilidad de dinamizar otras áreas de Galicia mantendrán y aprovecharán sus señales de identidad. Esto contribuirá a mostrar una mayor oferta de tipos de turismo en el territorio de Galicia.

En cuanto a las características básicas de la oferta de turismo de Galicia, se puede afirmar que la evolución en alojamientos fue una realidad; sin embargo, es fundamental continuar en esta línea con la finalidad de aumentar el número de turistas y mejorar la rentabilidad del sector (Vera, 1997; Besteiro, 1997; Rodríguez y Martínez, 2009). El turismo rural gallego ${ }^{1}$ necesita un análisis

1. Al que me referiré en más ocasiones a lo largo de este trabajo, pues guarda una relación muy directa con el turismo forestal. 
propio, ya que el comportamiento que tuvo en los últimos años no fue el esperado, pues su política pretendía que se convirtiese en una actividad que dinamizase ciertos territorios de carácter rural y la realidad fue bien distinta, al convertirse en una actividad complementaria o secundaria dentro del sector del turismo y de la socioeconomía en general. Pues se limitó a crear una red de alojamientos con una estructura arquitectónica «muy peculiar» y una dotación de actividades complementarias muy reducidas que limitaron en gran medida el desarrollo socioeconómico de las comarcas de carácter rural de Galicia. Por lo que la complementariedad que pueden ofrecer actividades como el turismo forestal es un factor a tener muy en cuenta para el desarrollo del turismo en general y del rural en particular (Cals, Capellà y Vaque, 1995; Ortuño, 2000; Calvo et al., 2003; Cánoves et al., 2003; Pérez y López 2005).

En cuanto a las características principales de la demanda turística en Galicia, el factor más determinante es la estacionalidad, con el resultado directo de producir una saturación en la temporada alta (verano y Semana Santa), y paro y pérdidas en el sector en la temporada baja. Aunque los años Xacobeos tengan un comportamiento propio no se deben tomar ni como referencia ni como el sustento del turismo en Galicia (Blanco y Benayas, 1994; Besteiro, 1997; Rodríguez y Martínez, 2009).

A pesar de esta estacionalidad, los datos y otras estadísticas oficiales muestran que el turismo es una de las actividades más importantes de la estructura socioeconómica de Galicia. Además, posee las mejores condiciones territoriales para aumentar su actividad y desarrollar otros tipos como el turismo forestal, que por un lado diversificaría la oferta en comarcas que se encuentran en desequilibrio con el resto de Galicia, como son ciertas áreas rurales y de montaña (Ancares, A Fonsagrada, O Eume, etc.). Asimismo, favorecería el proceso de desestacionalización que deben encarar los espacios gallegos centrados con exclusividad en un turismo de sol y playa.

\section{Características generales de un tipo de ecoturismo: el turismo forestal}

Dentro del amplio abanico de tipologías y actividades que se encuentran dentro del sector del turismo, una de ellas es el denominado ecoturismo. A su vez, dentro del mismo se ubica el turismo forestal. A continuación se exponen brevemente las características de estas actividades. Se debe aclarar que cada uno de los apartados en los que se analiza el ecoturismo tiene una relación y aplicabilidad directa con el turismo forestal.

Desde una perspectiva amplia, el ecoturismo se puede definir como aquellas actividades turísticas que se basan en la naturaleza, donde los visitantes viajan a ciertos territorios con la pretensión de apreciar su riqueza natural y paisaje. Desde esta visión general, ya se puede incluir el turismo forestal (paseo o visión de los montes, de los árboles, de la función sociocultural de estas áreas, etc.) como una actividad recreativa dentro del ecoturismo. En 1965, el turismo en la naturaleza se fundamentó en el respeto a la cultura y a la población local, en la inversión de los beneficios en la población local, en unos impactos 
ambientales reducidos y en una satisfacción de los visitantes elevada (Langoya y Long, 1997; Leslei, 2003; Ministerio de Industria, Turismo y Comercio, 2004). Unos años más tarde, en 1987, se definió al ecoturismo como: «viajar a áreas naturales sin contaminación con el objetivo específico de estudiar, admirar y disfrutar tanto del paisaje y sus plantas y animales, como las manifestaciones culturales existentes (pasadas y presentes) que se encuentren en estas áreas» (Buendía y Colino, 2001).

Por lo tanto, el turismo forestal va más allá de lo que es un paseo por un monte ${ }^{2}$ pues implica disfrutar de árboles singulares, palpar las actividades socioculturales, así como conocer la vida de la población local de estos territorios. Dentro de Galicia se comprueba que existen una serie de áreas, a las que se hará mención a lo largo de este artículo, con gran potencialidad natural dignas de ser «utilizadas» desde el punto de vista turístico, entre las que destacan sus montes, sus árboles monumentales, los paisajes forestales, etc.; todo esto a pesar del fuerte impacto del crecimiento urbano de ciertas áreas, la proliferación de masas arbóreas monoespecíficas, la construcción de vías de comunicación, la contaminación de ciertos cursos fluviales, etc. A este respecto, debe recordarse que la superficie forestal de Galicia representa cerca del 70\% del total y más del $50 \%$ es terreno arbolado (IV IFN, 2011). Antes de continuar con la exposición de las características del turismo forestal es necesario realizar un inciso y aclarar que en Galicia este se debe desarrollar en los montes y no en los bosques. Pues los montes son:

terreno poblado con especies forestales arbóreas como manifestación vegetal dominante y con una fracción de cabida cubierta por ellas igual o superior al $20 \%$. También comprende los terrenos con plantaciones monoespecíficas o poco diversificadas de especies forestales arbóreas, sean autóctonas o alóctonas, siempre que la intervención humana sea débil y discontinua, excluyendo las tratadas como cultivos. (Xunta de Galicia, 2001)

Mientras que bosque es «un ecosistema dentro del monte arbolado constituido por una estructura de árboles, arbustos y otros vegetales en el que domina el estrato arbóreo, con unas condiciones microclimáticas diferentes a las reinantes en su entorno y con una actividad funcional no influida por el hombre» (Xunta de Galicia, 2001).

Cabe destacar que la ética de la conservación, sin duda, ha sido uno de los fundamentos del desarrollo del ecoturismo, pero su crecimiento reciente, en muchos casos, fue gracias a los beneficios económicos que genera esta actividad tras una mínima inversión. En consecuencia, se puede afirmar que tras la expansión de las actividades turísticas responsables se encuentran más los intereses económicos que éticos. Una muestra de ello está en las dificultades que surgen a la hora de realizar una verdadera experiencia ecoturística en la

2. La Xunta de Galicia elaboró un programa denominado "Los Bosques de Galicia» que se limita a plantear nueve rutas por algunos de los «bosques» del territorio de Galicia. Se trata de la única actuación que mantiene relación con el turismo forestal (<http://www.turgalicia. es/portada-de-bosques-de-galicia>, 2014). 
medida que los montes son talados, los cursos fluviales contaminados y aumenta el impacto humano sobre el medio.

Además, el ecoturismo posee una potencialidad. Para su desarrollo necesita de las tres premisas que se incluyen dentro del «turismo sostenible»: ambiental (porque sin recursos naturales conservados el ecoturismo no existe), social (debe ayudar a las poblaciones en las que se desarrolla), económico (mejorar las condiciones de vida del país y de las áreas donde tiene lugar) (Regueiro, 1994; Barroso y Flores, 2003). El turismo forestal tiene como objetivo, por tanto, el disfrute de los recursos naturales, pero ayudando a la comunidad desde el punto de vista socioeconómico. A continuación se analizan por separado estos tres aspectos de la sustentabilidad, siempre enfocados al turismo forestal (Lage, 2003; Ortega, 2004; Rodríguez, 2004; Araque, 2005).

Desde el punto de vista ambiental, el turismo forestal puede ser muy efectivo como conservador del medio. De hecho, se están protegiendo especies y parajes en todo el mundo gracias a los ingresos que los turistas efectúan tras su contemplación y vivencia (Buendía y Colino, 2001; Leslei, 2003; Ministerio de Industria, Turismo y Comercio, 2004). Pero, como toda actividad turística, puede provocar impactos ambientales negativos, aunque suelen ser pequeños porque estamos ante un turismo no masificado. Entre los perjuicios que el ecoturismo puede conllevar, se pueden distinguir: los trastornos a la fauna y la flora; la contaminación, erosión y otros impactos en el territorio; la alteración intencionada de los recursos naturales (el ecoturista origina un gasto de recursos importante - agua, energía - que es necesario considerar) y determinados impactos visuales y acústicos.

Desde el punto de vista social, el turismo forestal puede aportar muchos beneficios a la población local, tales como dinero, empleo, infraestructuras, nuevas actividades económicas, es decir, un desarrollo económico importante en el área. Pero también puede ocasionar inconvenientes a los habitantes locales que podrían cambiar sus costumbres y tradiciones. Por otra parte, muchas veces son los peores puestos de trabajo, y los peor pagados, los que se dejan para la población local, pues esta no tiene experiencia o conocimientos suficientes para desempeñar misiones más importantes.

Desde el punto de vista económico, el turismo forestal es ya una fuente de ingresos importante en países como México, Perú, Argentina, Costa Rica o China, que ven en esta actividad una manera de conservar su naturaleza y al mismo tiempo obtener importantes recursos y beneficios (empleo, infraestructuras o incremento del PIB) (Theophile, 1996). Pero uno de los principales problemas del turismo forestal y del ecoturismo en general es que los ingresos que se obtengan no se reinviertan en el propio país de destino o en las áreas que se visitan. Los ingresos por ecoturismo deben ayudar al Estado en general, pero también a la región donde se encuentra o al área local, tanto para contribuir a su conservación como para que la población se vea beneficiada por su proximidad a un espacio acondicionado para su disfrute turístico. Este será el modo de que lo aprecien y respeten, además compensará los ingresos perdidos por la prohibición o limitación de diversas actividades. 
Otro de los inconvenientes del ecoturismo en el ámbito económico son sus fluctuaciones, su estacionalidad, a veces incluso más acusada que la que afecta al turismo en general, porque hay ciertos recursos naturales que solo pueden contemplarse en épocas muy específicas del año. Por lo que convertir el ecoturismo en un "monocultivo" puede traer consecuencias nefastas para un municipio, comarca o país (Terluin, 2003).

Hay muchos ejemplos de ecoturismo sostenible, en países como Kenia o Costa Rica, que están realizando una buena gestión, y para los que el ecoturismo es ya su principal fuente de ingresos. También Estados Unidos está aprovechando sus parques nacionales utilizando los recursos de forma racional.

Como ejemplos puntuales, en España destaca el centro de desarrollo sostenible «Les Planes del Son», situado en el Pirineo Catalán, en el valle de Àneu. Es un edificio absolutamente integrado en el entorno, y una de las mejores muestras de construcción sostenible para el ecoturismo en España (Bori-Sanz y Niskanen, 2002). En Galicia un posible ejemplo es el Monte Aloia, que se trata del primer espacio que tuvo un tipo de protección natural de Galicia y dentro de sus 746 hectáreas se puede disfrutar de un centro de interpretación, de rutas, de los paisajes forestales, etc.

A su vez, también hay que tener presente que dentro del turismo forestal, gracias a la experiencia de otros países, existen diferentes tipos de turistas forestales que es necesario conocer pues dentro de las grandes potencialidades forestales de Galicia y su diversidad, se pueden acondicionar las áreas forestales según el tipo de turistas que se consideren más adecuados para cada territorio. Estos turistas pueden clasificarse en cinco grandes grupos (Regueiro, 1994; Grundy y Le Breton, 1997; Lage, 2003):

- Aventureros-montañeros: buscan un reto o un desafío de la naturaleza, espacios naturales que explorar y realizar una actividad física intensa. Prefieren sobre todo los espacios de montaña.

- Naturalistas y admiradores de la naturaleza: buscan el contacto con la naturaleza y son muy cuidadosos con el medio natural. Aquí se engloban investigadores, estudiantes y conservacionistas.

- Campistas: a menudo buscan un lugar para descansar y un escenario agradable. Habitualmente buscan un mayor número de comodidades.

- Los turistas de naturaleza informados: están interesados en el relieve, las aguas, la flora y la fauna, y están muy documentados. Realizan viajes específicos para visitar áreas protegidas.

- Los turistas de naturaleza ocasional: normalmente están poco informados sobre los espacios que visitan, las estancias son breves, y forman parte de un viaje más amplio. Buscan principalmente los paisajes espectaculares y muy conocidos.

Por lo que ya en este punto, se puede indicar que el turismo forestal es una actividad que como elemento central tiene el monte en el que los turistas realizarán sus rutas, la contemplación del paisaje, la convivencia con la población 
local —que tanta vinculación tuvo con estas áreas a lo largo de la historia—, el conocimiento de la cultura forestal gallega, las actividades económicas que se desarrollaron y desarrollan en los montes, etc. Pero hay que hacer hincapié en que el turismo forestal va más allá del propio monte, ya que la visión de determinados árboles monumentales, alojarse en casas de turismo rural y poder, en ciertos momentos, acercarse a los montes o áreas forestales singulares, asistir a un centro de educación ambiental a escuchar las peculiaridades y las funciones socioculturales de los montes, la recolección de setas o castañas; eso también es turismo forestal.

En Galicia, se detecta una clara potencialidad para desarrollar el turismo forestal, pues el monte ocupa un lugar importante en su cultura y en su historia, proporcionando una amplia gama de bienes y servicios para toda la sociedad. El aprovechamiento del monte y la cultura forestal están muy unidos a la propia identidad del territorio y de la colectividad (Bouhier, 1979 y 1984; Prada, 1991; Fernández, 1990; Balboa, 1999).

Una muestra de su significación es que los montes ocupan más de 2 millones de hectáreas, lo que representa el $70 \%$ de la superficie de Galicia. Además, la mayoría se encuentran cubiertas por masas arbóreas, cerca de 1,5 millones de hectáreas, lo que concede mayores posibilidades de desarrollo al turismo forestal, algo más de 100.000 hectáreas están ocupadas por áreas arbóreas poco densas y en más de 600.000 hectáreas predominan las especies arbustivas, matorrales y herbáceas (IV IFN, 2011).

Además, el $48 \%$ de los municipios gallegos poseen más de una hectárea forestal arbolada por habitante (ver Mapa 1), lo que indica que un porcentaje elevado de municipios disponen de la materia prima necesaria para el desarrollo del turismo forestal como tipología turística principal. Mientras que dentro del $52 \%$ de los municipios que tienen menos de una, pero más de media hectárea forestal arborada por habitante, el turismo forestal se podría orientar hacia una actividad complementaria de otras tipologías de turismo como el de sol y playa o el turismo rural.

A pesar de que los montes con predominio de especies arbóreas como el pino y el eucalipto son los mayoritarios, cerca de un $40 \%$ están ocupados por robles y castaños, especies que además de ser las propias de los montes gallegos permiten que en torno a ellas se constituyan verdaderos montes típicos de Galicia con una estructura arbustiva y herbácea consolidada. De todos modos, cabe destacar que existen ciertas áreas en Galicia donde predominan especies de repoblación (pino y eucalipto), que también poseen características para ser aprovechadas desde el punto de vista turístico. Entre las mismas, la masa arbórea de eucaliptos que se encuentra en el norte de la provincia de Lugo, en la comarca de A Mariña Lucense, que se llega a catalogar como el mayor eucaliptal de la Europa occidental (Miramontes, 2010).

En cuanto a la localización de las áreas que tienen mayor potencialidad desde el punto de vista del turismo forestal en Galicia, se pueden hacer varias categorías.

Las áreas periurbanas, donde el predominio de especies arbóreas está muy marcado por especies de pino y eucalipto, y el paisaje aparece bastante modi- 

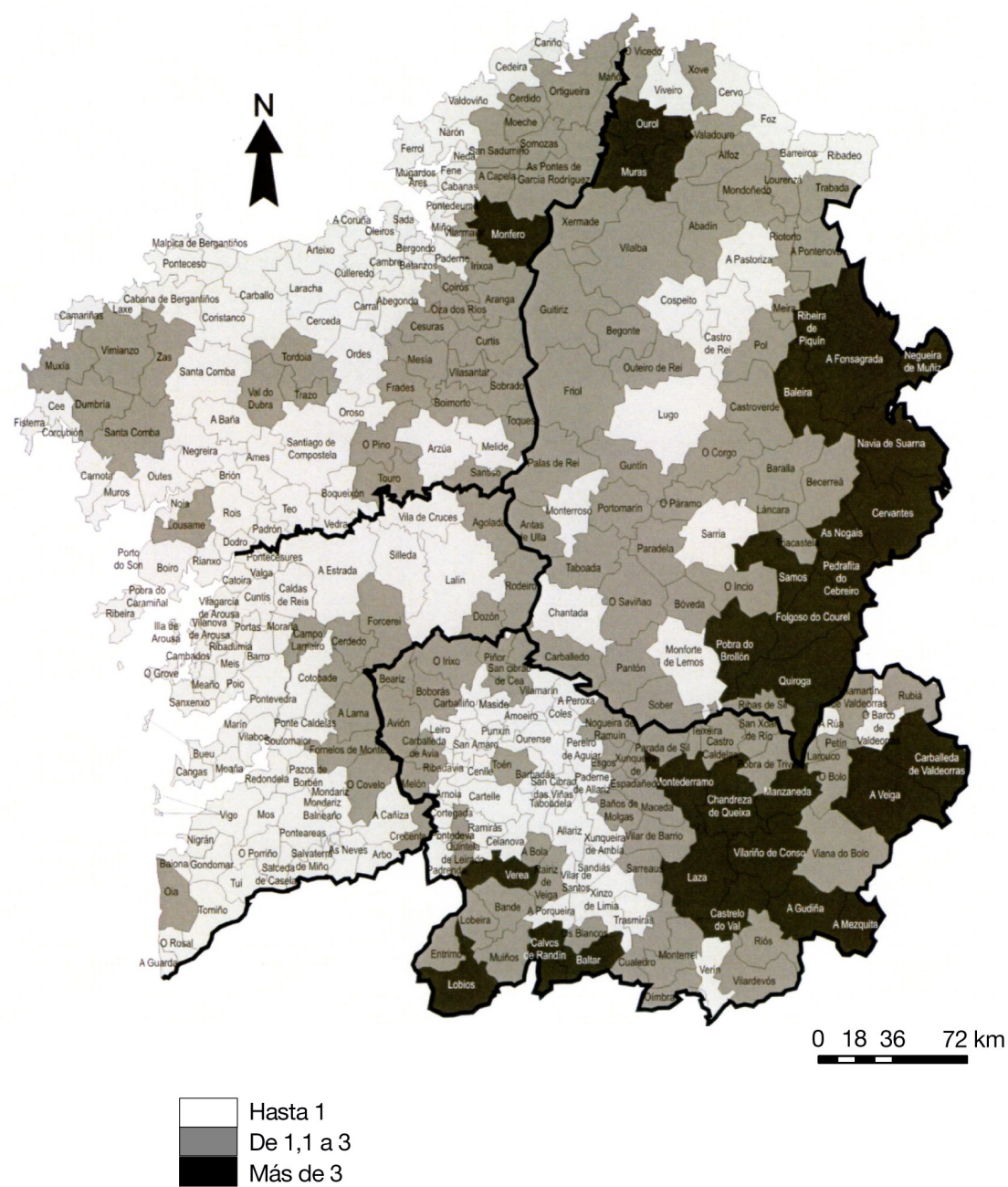

Mapa 1. Superficie forestal arbórea (ha) por habitante a escala municipal en Galicia.

Fuente: elaboración propia a partir de datos del Cuarto Inventario Forestal Nacional: Galicia. MAGRAMA (2011).

ficado por la acción del hombre; por otro lado se encuentra muy próximo al mayor volumen de demandantes de esta actividad.

Otra área con unas características naturales similares a la periurbana (además de los mayores volúmenes demográficos), es toda la franja litoral gallega, principalmente la provincia de Pontevedra. Las áreas forestales podrían ser un complemento más a la pujante actividad turística tradicional de sol y playa que se desarrolla en todo este espacio. 
De todos modos, el área que posee mayores peculiaridades para ser beneficiaria de una actividad turística forestal sostenible engloba todo el interior de las provincias de A Coruña y Pontevedra, y en mayor medida, las áreas más orientales de las provincias de Lugo y Ourense. El paisaje se encuentra mucho menos antropizado, la riqueza forestal es mucho más heterogénea y entre otras peculiaridades conserva la estructura de los montes tradicionales $y$, por otro lado, no existe una competitividad tan aguda entre los diferentes usos del territorio. Además el desarrollo de esta actividad turística se puede convertir en uno de los elementos que generen mayores beneficios socioeconómicos para las localidades.

En último lugar se hace referencia a los espacios naturales protegidos, para decir que la política de estos parques con respecto al turismo y su impacto sirve para controlar el desarrollo del turismo y el progreso del ciclo de vida de los destinos que se acaban de mostrar. Los parques nacionales y naturales se conciben principalmente como instrumentos y entidades de conservación de la naturaleza, mientras que su función turística es generalmente secundaria. Sin embargo, hoy en día las autoridades de los parques tienen que afrontar el dilema que supone, por un lado, el mantenimiento rígido de su política de conservación ambiental y control de acceso y, por otro, su promoción turística. Además hay que recordar que dentro de muchos de los parques naturales de Galicia la peculiaridad que les permitió adquirir algún tipo de protección medioambiental fue el predominio de hectáreas de monte.

Por todo ello, el turismo forestal es una actividad que como elemento central tiene al monte en el que, como ya se mencionó, los turistas realizarán sus rutas, observarán determinados árboles monumentales, se alojarán en casas de turismo rural o asistirán a un centro de educación ambiental. Todas estas actividades son las que definen al turismo forestal y las que le otorgan capacidad suficiente para atraer turistas, pero, a su vez, el turismo forestal también puede ejercer la función de recurso complementario de otros tipos de actividades, como el turismo rural o el ecoturismo.

\section{El monte gallego como recurso turístico}

Desde mediados del siglo xx, la mayoría de los montes de los países desarrollados experimentaron profundos cambios paisajísticos y funcionales. Estos espacios perdieron fuerza en su función de producción de recursos primarios, pero empezaron a asumir otras nuevas funciones relacionadas con la protección y el esparcimiento al aire libre. De este modo, lejos de diluirse el papel económico y social que desempeñaban, este se reforzó de modo considerable, excediendo ampliamente los estrechos límites de actividad en los que se desarrollaban las sociedades rurales tradicionales (Montiel, 2003; Donaire y Gordi, 2003; Lage, 2003).

La aparición de las nuevas funciones recreativas en los montes está asociada principalmente al incremento de los niveles de desarrollo y al constante proceso de urbanización de la población. Del primero de estos hechos se derivó una mayor disponibilidad de rentas personales y un aumento de los periodos 
vacacionales de la población. Además, la concentración de la población en las ciudades y áreas de influencia, fue provocando de modo irremediable una insatisfacción creciente entre muchos ciudadanos, angustiados por los ritmos estresantes que impone el modo de vida de carácter urbano. Si a todo esto se une el incremento en la capacidad de desplazamiento que trae consigo la generalización de los medios de locomoción personales, se explica el espectacular auge que experimentan las funciones recreativas en una gran parte de los montes españoles y la que pueden alcanzar en concreto los montes gallegos (Donaire y Gordi, 2003; Lage, 2003; Ortega, 2004).

Por todo ello, a lo largo del apartado se elaboran una serie de consideraciones que permitirán conocer las peculiaridades del monte gallego como recurso turístico. En primer lugar, con la preocupación de mostrar las potencialidades y debilidades que tienen los montes desde el punto de vista de su función sociocultural. Una vez que ya se conozca esta función, se profundiza en estudiar los usos y los valores recreativos de los montes gallegos.

Desde mediados del siglo Xx, ya se plantearon una serie de estudios en los que se habla de la tercera dimensión del monte, entendida y analizada desde diferentes ciencias como su potencialidad social, cultural y recreativa, yendo más allá de la visión que les concedía la única finalidad de producir madera. Se pueden destacar los trabajos de Susmel (1968), biólogos como Gómez-Limon (1995), geógrafos como Valenzuela, (1984), Font y Tribe (2000), Montiel (2003), Donaire y Gordi (2003), Gómez y Mata (2006) o ingenieros forestales como Hermanin (1988).

A su vez, también se debe tener presente que en esta nueva visión del monte influye de un modo directo el abandono rural (demográfico y económico) y las nuevas demandas de la población de las áreas urbanas. Por ello, en muchos países europeos los montes se convierten en un espacio sujeto a nuevas dinámicas. Cada vez existe una mayor conciencia sobre la planificación multifuncional de los montes, por medio de la cual, en Europa y Norteamérica se persigue una visión que como mínimo tiene tres alicientes: el productivo, el ambiental y el social (Donaire y Gordi, 2003; Montiel, 2003). Un claro ejemplo se encuentra en los informes de la Estrategia Forestal Española (1999) y en el Plan Forestal Español (2002-2032), ambos realizados por el Ministerio de Medio Ambiente, y en los que destaca la importancia sociocultural de los montes. Concretamente, uno de sus objetivos es promocionar su uso recreativo responsable que contribuya a la divulgación de una nueva cultura forestal.

El monte es un recurso turístico cada día más importante. Aunque dentro de Galicia son prácticamente inexistentes los montes aprovechados desde este punto de vista, solo hay que navegar por las webs de asociaciones de casas de turismo rural, de espacios naturales protegidos u ojear las páginas de revistas turísticas y comprobar cómo la palabra monte o bosque aparece como uno de los reclamos turísticos del lugar o para darnos cuenta del gran número de espacios forestales descritos. Dentro de estas descripciones, además de su valor natural, preocupa mostrar las funciones culturales y sociales que realizan los montes (<www.turgalicia.es $>$, 2014). 
Los montes son territorios que forman parte de la cultura popular, hecho que se refleja en distintos hechos como la existencia de asociaciones que muestran el aprecio y la estima por la cultura forestal. A modo de ejemplo se pueden citar la constitución de asociaciones como Club d'Amics dels Arbres per la Terra de Barcelona o la Asociación de Amigos del Árbol en Rosario (Argentina). Así también se pueden mencionar las celebraciones del día del árbol o las diferentes páginas web sobre patrimonio forestal, las dedicadas a árboles monumentales (<http://old-trees.tripod.com $>$ ) y las numerosas publicaciones de catálogos nacionales como el de Francia (Bourdu, 1988), de áreas de Estados Unidos (Van Pelt, 2001) o de Cataluña (Vinyeta, 1995), como ya recogían Donaire y Gordi (2003).

Existen árboles y montes de fama internacional y que son reclamo turístico, por ejemplo la secuoya llamada General Sherman Tree del Sequoia Nacional Park de Estados Unidos, los bosques de Viena, los de Fontainebleau en las proximidades de París, el Crooked Forest en el municipio de Nowe Czarnowo, en el noroeste de Polonia, donde 400 ejemplares de pino plantados en 1930 tienen sus troncos curvos que parecen describir una hoz en su base. En Madagascar, la avenida de los Baobabs tiene ejemplares de más de 30 metros de altura y 800 años de antigüedad. El bosque de bambú de Sagano (Japón), con ejemplares de más de 20 metros de altura o la selva de Irati en Navarra. Sobre esta temática también es importante apuntar el buen número de guías dedicadas a descubrir montes. Por ejemplo, de España (Alonso, 2000), de Cataluña (Gordi, 2000) o de Francia (Plaisance, 1997). A su vez, también hay árboles singulares o monumentales que tienen una significación ideológica como el árbol de Guernica en el País Vasco o el Pi de les tres branques, en Cataluña. En consecuencia, la población se siente atraída por los árboles monumentales y por los montes peculiares o con encanto (Donaire y Gordi, 2003; Montiel, 2003).

En Galicia también hay un considerable número de montes y árboles en torno a los que se constituyeron historias y la etnografía de muchos territorios. Por ejemplo, en el Pazo de Trasalba en el municipio de Amoeiro (Ourense), donde se crió y falleció el ilustre geógrafo-escritor Ramón Otero Pedrayo. Existió un ejemplar de abeto que plantó el padre de este intelectual al cual puso el nombre de O Irmanciño, al que el intelectual gallego siempre tuvo gran cariño hasta que en 1972 una tormenta lo destruyó. En muestra de su aprecio recogió los restos y construyó un ataúd en el que guardó los restos de su hermano (Lage, 2003; Rodríguez e Izco, 2003).

En esta relación cultural que se presenta, cabe mencionar que existe una obra titulada Árbores Monumentales no Patrimonio Cultural de Galicia (ver Figura 1) (Rodríguez e Izco, 2003) editado por la Xunta de Galicia, que cataloga un total de 344 de los mejores ejemplares de árboles gallegos atendiendo a muy diversos criterios, antigüedad, representatividad, tamaño, singularidad, etc. Un ejemplo de los citados en esta obra es el ejemplar de eucalipto, plantado a finales del siglo xIx, en el Souto da Retorta, en el municipio de Viveiro (Lugo), denominado Avó de Chavín. Se trata del árbol más alto no solo de Galicia sino de toda España, ya que supera los 70 metros. También se men- 

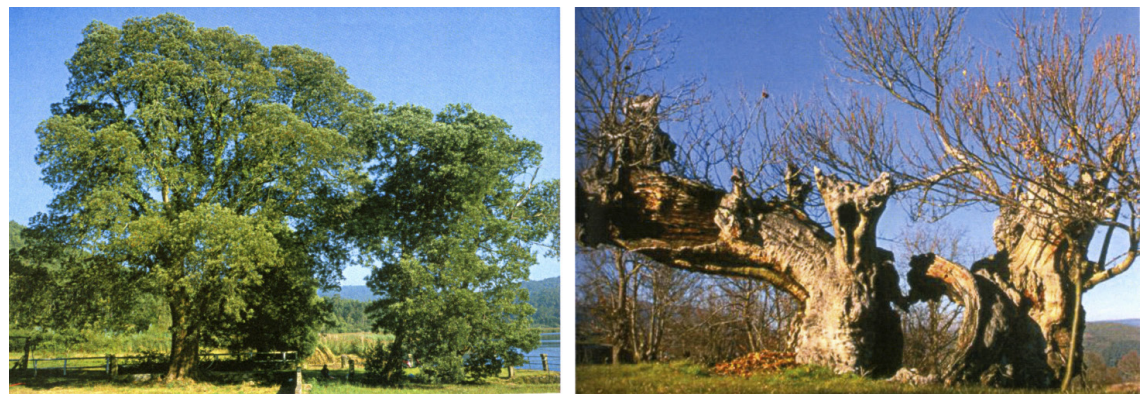

Figura 1. Acacia de madera negra de la Casa de Enxido (Outes-A Coruña) y castaño de A Regadita (Pobra de Trives-Ourense).

Fuente: Árboles monumentales... (Carlos Rodríguez Dacal y Jesús Izco, 2003). Xunta de Galicia.

cionan los que presentan el mayor diámetro, como los castaños de Costa y el de Pombariños, ambos en Ourense; sus troncos alcanzan la docena de metros de grosor. Entre ejemplares más antiguos - y por eso representativos- se mencionan robles, castaños, alcornocales y tejos. Estos superan de largo los 500 años y se puede destacar el roble del Pazo de Cartelos, los castaños del Bosque de Pombariños o el alcornoque de Balboa en el municipio da Estrada (Pontevedra).

Otro aspecto que también se analiza en este trabajo es el nombre con el que se bautiza a algunos árboles, que lleva detrás una historia o tradición, como la famosa Pravia de Vilalba, un arce blanco de 15 metros de alto que se levanta a pocos metros del Parador. En el paseo da Ferradura, en Santiago de Compostela, se sitúa un abeto que lleva el nombre de Perona, en honor a Evita Perón, ya que esta argentina plantó este árbol el 19 de junio de 1947, utilizando además tierra de la casa en la que naciera la ilustre escritora gallega Rosalía de Castro. En definitiva, un apego cultural de los árboles recogido en todos estos elementos culturales (Lage, 2003; Rodríguez, 2004).

A su vez, también se puede hablar de ciertos montes, como espacios cargados de mitología y simbología (Nogué, 1986). Desde tiempos remotos, los montes fueron el lugar donde situar relatos místicos, fantásticos, religiosos... A escala internacional, el Hoia-Baciu, en la rumana de Cluj-Napoca, que se conoce como el bosque más siniestro del mundo. Apodado como «el triángulo de las Bermudas de Rumanía», acumula muchas historias de desapariciones misteriosas. Incluso la población local tiene miedo de entrar en él. Realidad o sugestión, pero existen relatos de personas que han salido del bosque con arañazos, dolores de cabeza, erupciones o náuseas. Su carácter paranormal incluye fenómenos como luces, voces, apariciones... Otro ejemplo es proporcionado por los encinares y pinares del macizo de El Montnegre (Cataluña), donde se encuentra el dolmen «Pedra gentil», lugar donde según cuentan las leyendas se reunían las brujas. O la higuera del Meco de O Grove, en el municipio de O Grove (Pontevedra), que se halla suspendida entre rocas, que hereda este 
nombre porque dicen que allí colgaron a un odioso eclesiástico que se llamaba Meco. En la capilla de Santa Margarita en Mourente (Pontevedra) se encuentra un roble monumental que es venerado y respetado por todos los vecinos del municipio que no permiten que se toque ni pode. Además cuentan que las promesas que se hacen bajo su copa no pueden romperse nunca (Donaire y Gordi, 2003; Lage, 2003; Rodríguez, 2004).

Según la obra de Carlos Rodríguez y Jesús Izco (2003), también se puede analizar la localización territorial a escala municipal de los árboles monumentales de Galicia (ver Mapa 2), con la finalidad de conocer cuáles son los territorios en los que se podría pensar que tienen una mayor potencialidad desde el punto de vista del turismo forestal, puesto que llevan ya tras de sí una cultura que se podría aprovechar para convertirlo en este tipo de recurso.

En primer lugar, destaca el desequilibrio que existe entre la fachada occidental y la oriental de Galicia, dado que en la primera se localiza más del $72 \%$ de estos recursos turísticos. De todos modos, casi la tercera parte de los municipios gallegos tiene alguna representación de árboles monumentales, concretamente en 97 de ellos.

Otra característica de localización es la diferencia entre el medio urbano y el rural. De hecho, en el urbano es donde está un mayor número de árboles, en gran medida como consecuencia directa de albergar grandes pazos y jardines. Los ejemplos de los municipios de Vigo, Vilagarcía de Arousa, Soutomaior, Santiago de Compostela o Padrón así lo confirman. Es necesario reiterar la significación de los pazos, porque en estas y otras propiedades de la antigua nobleza gallega se encuentra casi la mitad de los árboles monumento de Galicia. Por ejemplo, el de Santa Cruz de Ribadulla (Vedra), Mariñán (Bergondo), Soutomaior (Soutomaior) y Oca (A Estrada). Dentro de los jardines municipales destaca el Xardín Artístico (Padrón), la Alameda do Campo da Estrela, el paseo da Herradura y la Carballeira de Santa Susana (los tres en Santiago de Compostela) o los Xardíns de Méndez Núñez (A Coruña).

A estas relaciones de los montes y los árboles con la cultura popular hay que añadir que fueron fuente de inspiración de poetisas y escritores. Algunos ejemplos se encuentran en la web de los parques naturales italianos (<www. parks.it $>$ ) o en la red de bibliotecas de Barcelona (<http://w110.bcn.cat/ portal/site/Biblioteques $>$ ) que ofrecen itinerarios literarios. Uno de estos itinerarios se realiza en los bosques de Collserola y es una actividad guiada por un monitor y un actor, que explican cuentos en el interior del bosque y sus características naturales, combinando la contemplación del bosque con la lectura (Donaire y Gordi, 2003).

Otra función de los montes se puede definir como la de ser un escenario artístico. A escala internacional, uno de los ejemplos más notables es el bosque sagrado de Bomarzo, en Viterbo (Italia), donde en el siglo Xvi el conde Vicino Orsini mandó esculpir un conjunto de esculturas situadas en el interior del bosque que fueron utilizadas como referente literario en la obra de Manuel Mújica Lainez, Bomarzo (Roquero, 1999; Donaire y Gordi, 2003). En España hay dos ejemplos dignos de mención, uno se trata del bosque mágico de Oma 


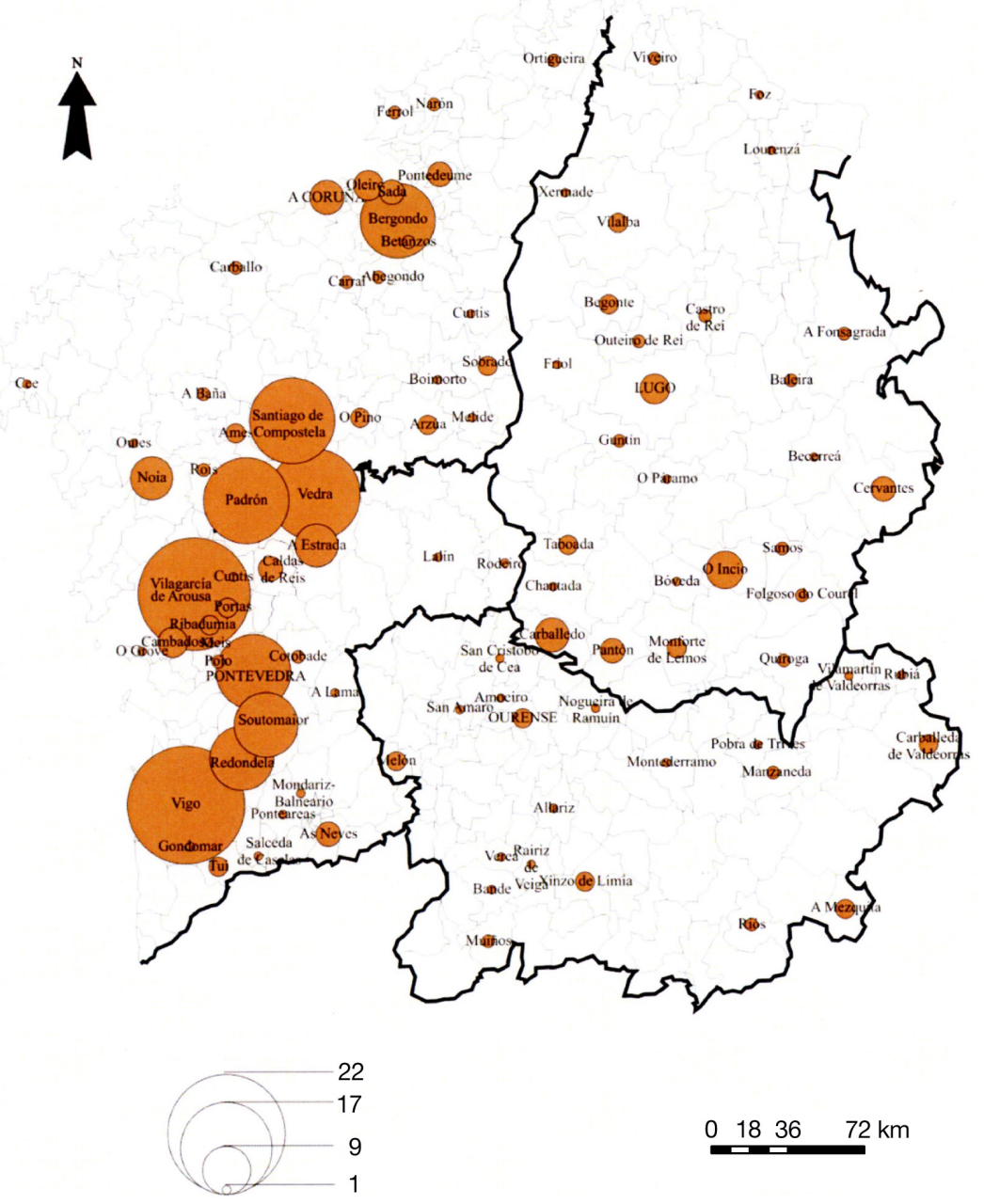

Mapa 2. Localización de los árboles monumentales de Galicia a escala municipal.

Fuente: Árboles monumentales... (Carlos Rodríguez Dacal y Jesús Izco, 2003). Xunta de Galicia.

dentro de la reserva de la biosfera de Urdaibai (Vizcaya). Este bosque es una repoblación de Pinus Pinaster en la que los troncos de los 500 árboles fueron pintados por el pintor y escultor Agustín Ibarrola con colores vivos y significados variados. Antes de continuar con la exposición de otro de los mejores ejemplos de montes con peculiaridades artísticas dignos de ser aprovechados desde el punto de vista turístico, cabe hacer una reflexión: señalar que los montes como recurso turístico no se tienen porque limitar a espacios naturales poco transformados por el hombre o que destaquen por su biodiversidad 


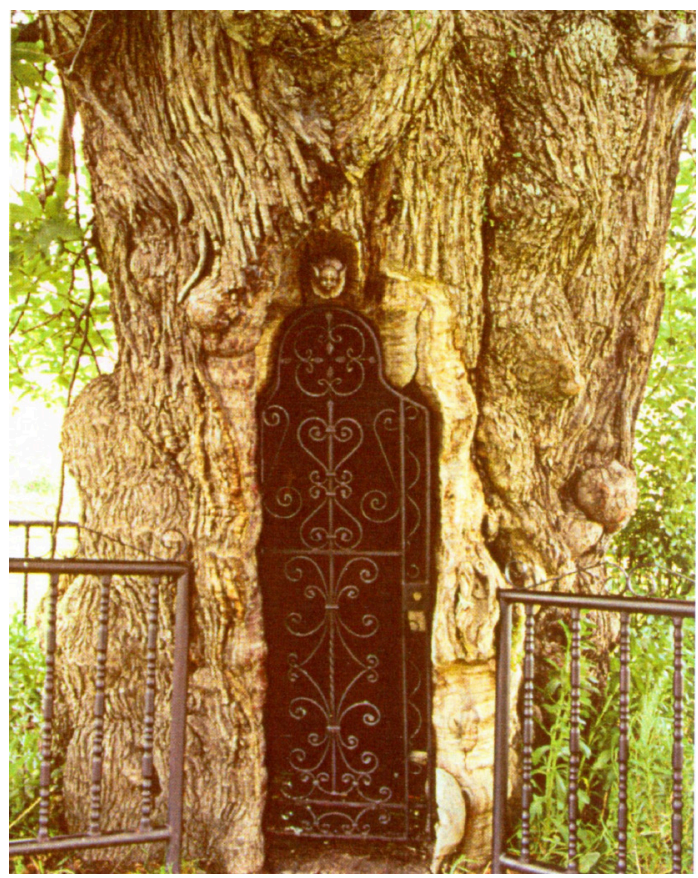

Figura 2. Castaño de la Capilla (Begonte - A Coruña).

Fuente: Árboles monumentales... (Carlos Rodríguez Dacal y Jesús Izco, 2003). Xunta de Galicia.

o antigüedad de sus masas arbóreas, sino que deben ir más allá; tal y como se acaba de mostrar, un monte de repoblación puede destacar más por el número de personas que se desplazan para recorrerlo que por su generación de madera destinada a la industria transformadora. Otro buen ejemplo de bosque vinculado al arte se encuentra en el bosque de Can Ginebreda, situado en El Pla de l'Estany (Girona). Se trata de un bosque privado en el que también hay esculturas, pero quizás lo más innovador es que se puede visitar el taller del escultor que se encuentra en el propio bosque. Al tratarse de una propiedad privada es necesario pagar entrada (Donaire y Gordi, 2003). En Galicia el ejemplo más similar es el castaño de la Capela de Begonte (A Coruña) al que no cesan de llegar excursiones desde hace treinta años, y en su interior ha habido velas y agua bendita (ver Figura 2).

También se puede hablar del carácter sagrado de algunos montes y árboles, pues son muchas las tradiciones, religiones y creencias que utilizan el árbol como expresión de un lenguaje. En consecuencia, cada árbol tiene su simbología y a veces llega a ser de una sociedad, como en el caso del robledal que es el monte y el árbol del pueblo vasco.

Este tipo de respeto a ciertos árboles y montes en Galicia también viene de antiguo. De hecho, bajo las copas de conjuntos de robles se celebran gran canti- 
dad y variedad de ferias. Una de ellas es la Feira de San Martiño de Calo en Teo (A Coruña) que tiene más de 200 años de antigüedad; se celebra anualmente y congrega a jinetes, caballos y visitantes de toda Galicia. La Carballeira de Francos, que también se conoce como la Carballeira de San Martiño, donde se celebra la feria en un hermoso paraje con una superficie aproximada de 15.000 $\mathrm{m}^{2}$, repartidos en huertas de titularidad pública y privada, lugar de paso de una de las rutas de peregrinación a Santiago de Compostela, el Camino Portugués. La Feira de Parga en Guitiriz (Lugo) es otro ejemplo de una festividad en la que se concentran todo tipo de productos agrícolas y ganaderos dentro de un recinto de $40.000 \mathrm{~m}^{2}$, que contiene gran cantidad de arbolado, entre el que destacan sus robles y castaños centenarios.

En cuanto a un ejemplo de árboles sagrados y de fuerte carácter religioso destaca el Carballo de Vilardefrancos en Carballo (A Coruña), llamado de San Antonio, al que se le atribuyen poderes casamenteros, probados por la costumbre de encestar piedras en una de sus oquedades por parte de los pretendientes. Si hay "canasta", tal vez se produzca el enlace.

A pocos kilómetros, en Sanfíns en Vimianzo (A Coruña) existe otro ejemplar al que se le atribuye la facultad de curar las hernias de los niños, cumpliendo un determinado rito. Hay vecinos que dan fe de sus efectos curativos, aunque no se probaron desde que operarios municipales le cortaron unas ramas hace unos años.

Otra singularidad excepcional está en el Xardín Botánico-Artístico de Padrón (A Coruña): la Coroa de Cristo, así llamada por su forma. Es un árbol del amor (especie de la que dicen que se colgó Judas), todo un prodigio de trabajo en un recinto en el que casi cada planta es una joya digna de ser visitada y observada.

En definitiva, ejemplos que acercan esa vinculación del hombre con los árboles, desde el punto de vista cultural y, por lo tanto, aprovechable también como recurso turístico.

En cuanto a la procedencia y al predominio de las especies arbóreas dignas de ser catalogadas como monumento, de las 117 especies, 97 son exóticas frente a las 20 autóctonas. Esta característica aporta una nueva potencialidad turística forestal de Galicia, dado que como ya se indicó, el turismo forestal no se reduce exclusivamente a áreas de monte autóctonas poco transformadas por el hombre o con una biodiversidad natural bien conservada, sino que determinadas figuras y conjuntos de masas arbóreas foráneas bien cuidadas, conservadas y adecuadas a las características del medio natural pueden convertirse en verdaderos recursos turísticos.

De todos modos, las especies autóctonas que destacan sobre las demás son el roble o carballo (Quercus robur), seguido del castaño o castiñeiro (Castanea sativa). Además de su monumentalidad y belleza, dignas de ser utilizadas como recurso turístico, se trata de especies que permiten que su sotobosque se encuentre en un perfecto estado natural y conserve el valor social y de identidad de Galicia, así como la lucha contra los incendios forestales y la no adulteración del suelo sobre el que se asientan. 


\section{Los usos y los valores recreativos del monte}

El impulso de los usos y los valores recreativos del monte transcurre paralelo al desarrollo económico y natural. El avance de la sociedad de consumo, entretenimiento y recreo traspasa las barreras sociales. El monte se vincula a nuevos estilos de vida que desbordan los antiguos referentes de su uso agrario-ganadero. Además de potenciar su utilidad tradicional, hay que introducir nuevas posibilidades de uso de los montes gallegos (Anderson, Clément y Crowder 1998). A sus magníficas características naturales se unen una serie de hechos que permiten el desarrollo del turismo forestal (la mejora de infraestructuras viarias, accesibilidad y movilidad de la población, etc.).

Entre finales de la década de 1980 y principios de la de 1990 tuvo lugar, a escala de España, el surgimiento de iniciativas de turismo relacionadas con los espacios rurales. Este tipo de turismo se centró en ofertar una serie de alojamientos de determinadas características, que tras el paso de los años muestran que su utilización como recurso en muchas ocasiones está obsoleta e infrautilizada, ya que para la perfecta dinamización de los territorios en los que se localiza y para el aprovechamiento de las potencialidades sociales y naturales que suelen tener estos espacios, es necesario diversificar la oferta de usos, recursos y actividades complementarias que vayan más allá del alojamiento.

Por esto, el monte es y se debe considerar como un elemento que diversifica las ofertas de consumo de las áreas rurales, ya que en ellas es donde se encuentran las áreas susceptibles de ser un recurso turístico (Donaire y Gordi, 2003; Lage, 2003; Rodríguez, 2004).

\subsection{El monte y el turismo rural}

En cuanto a la localización de las casas de turismo rural en Galicia (ver Mapa 3) se comprueba que existe una cierta heterogeneidad, ya que se ofrece este tipo de alojamiento en municipios del litoral, del interior, de carácter urbano, rural, mejor o peor enlazados con las vías de comunicación, etc. De todos modos, una de las características es la localización de un número considerable de estos alojamientos en municipios que poseen altos valores en cuanto a hectáreas de superficie forestal arbórea.

Según los estudios e informes de diversos autores (Blanco y Benayas, 1994; Ruiz, 1995; Besteiro, 1997; Montiel, 2003) e de instituciones o empresas públicas como TURGALICIA, S. A., el turismo rural gallego se caracteriza por ser una actividad económica que se apoyó en subvenciones para convertirse en una de las principales fuentes de ingresos de la población de determinadas áreas gallegas que han padecido un continuo éxodo rural, abandono de las actividades agrícolas y ganaderas, de las propiedades, etc. Con todo, la situación actual de esta actividad presenta una marcada estacionalidad, próxima a llegar a límites de saturación de oferta de alojamiento. Además, en muchas ocasiones estos alojamientos presentan una calidad de infraestructuras y servicios más que mejorables, que en el mejor de los casos están 


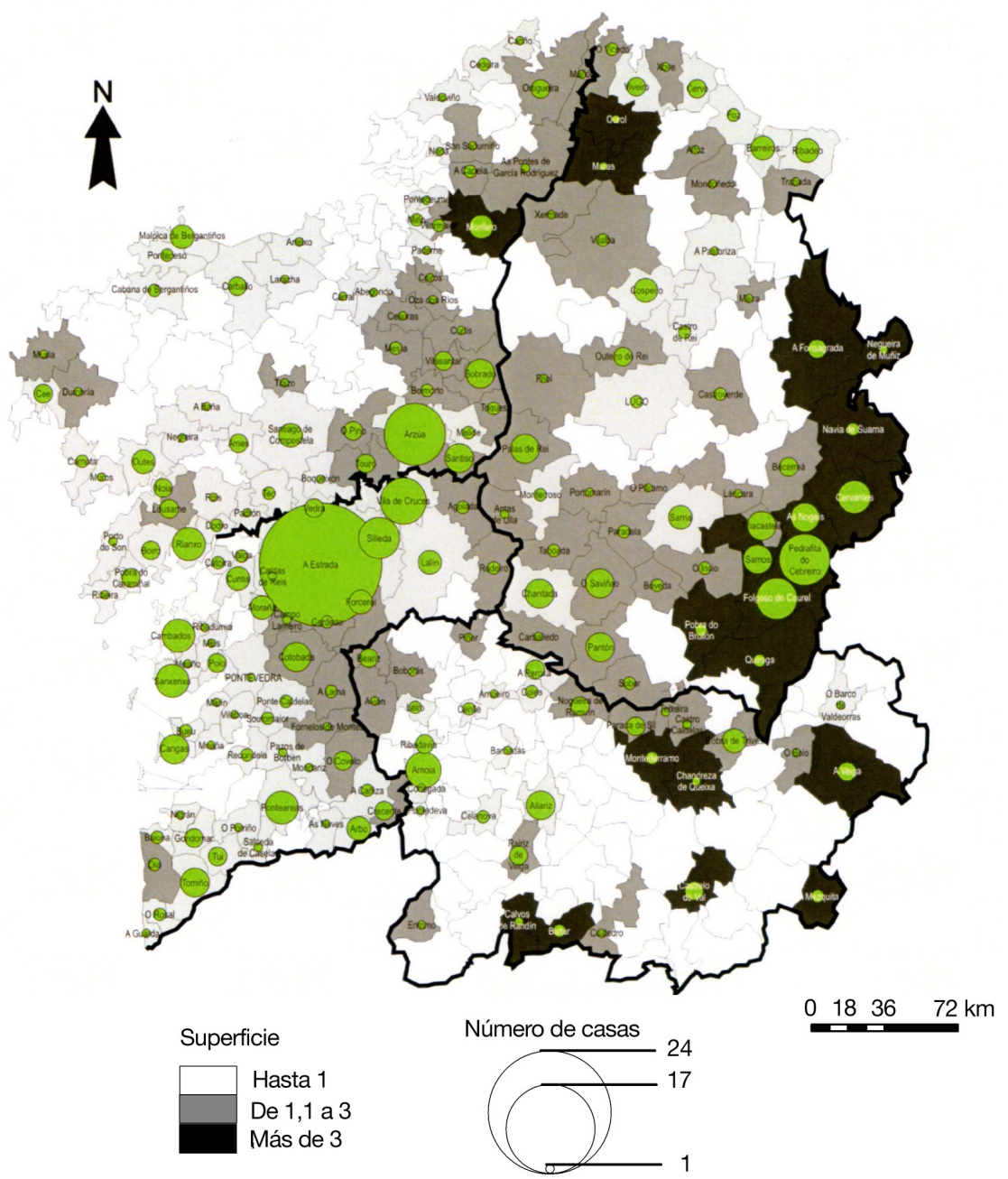

Mapa 3. Localización de las casas de turismo rural y la superficie forestal arbórea (ha) por habitante a escala municipal en Galicia.

Fuente: elaboración propia a partir de datos del Cuarto Inventario Forestal Nacional: Galicia. MAGRAMA (2011) y Turismo Rural 2014, Xunta de Galicia (2014).

ejerciendo la función de ser una actividad secundaria o complementaria de la población de las áreas rurales de Galicia (Blanco y Benayas, 1994; Besteiro, 1997; Montiel, 2003).

De todos modos, más allá de esta infrautilización de las potencialidades turísticas del rural gallego, también existen bastantes casos de alojamientos 
que presentan un magnífico comportamiento económico, y ofrecen un amplio abanico de servicios y ofertas turísticas que van más allá de la pernoctación.

Por este motivo, además de mejorar ciertas infraestructuras y servicios dentro del turismo rural, lo más importante es ampliar la oferta de actividades complementarias que realmente potencien y mejoren la calidad de vida de la población de determinadas áreas de Galicia. Entre estas actividades destacan los usos y los valores recreativos y turísticos del monte.

De hecho, en la actualidad se comprueba cómo en los municipios donde las masas arbóreas tienen cierta significación ya existe un número considerable de casas de turismo rural (Pedradita do Cebreiro o Folgoso do Courel) y otras que, dadas sus características naturales, aún podrían tener mayor representatividad como A Fonsagrada o Quiroga. Con todo, otros municipios que poseen una rica masa arbórea como Vilariño de Conso, Viana do Bolo o A Gudiña, no tienen ningún establecimiento de turismo rural, mientras que territorios con un carácter más urbano y una estructura socioeconómica más diversificada poseen un considerable número de establecimientos de turismo rural (Ponteareas o Cangas).

En Galicia se considera que es sumamente necesaria una ordenación territorial del turismo rural. Dentro de esta ordenación se deben tener muy presentes las características socioeconómicas de los territorios y solo subvencionar nuevas casas o mejorar las existentes que posean una serie de recursos complementarios a los de alojamiento como es el turismo forestal (rutas de senderismo, contemplación de paisajes forestales, árboles monumentales, etc.) con lo que se darían las características idóneas para potenciar su desarrollo y el del territorio en el que se localizan.

\subsection{El monte y los campings}

En cuanto a otros tipos de ofertas de alojamiento en las áreas rurales se encuentran los campings. Estos alojamientos suelen ser demandados por un porcentaje elevado de personas que se interesan por el paisaje y desean pasar sus vacaciones o periodos de descanso en contacto con la naturaleza. Estos son los denominados ecoturistas, que practican el turismo de la naturaleza donde se incluye el turismo forestal. En la mayoría de los casos el hecho de disponer de un camping en un área natural y forestal, o en las proximidades, suele ser un valor añadido a los usos y valores recreativos de ese monte. Además, los campings poseen la potencialidad de ser unos equipamientos que suelen estar en concordancia con su entorno, con lo que el impacto en el medio natural suele ser menor. De todos modos, también existen áreas naturales que con la intención de dinamizarlas turísticamente han sido escenario de una saturación de actuaciones que las han deteriorado y saturado (asfaltado de todas las vías de comunicación, edificaciones, influencia en los ciclos naturales de la flora y fauna, etc.).

En cuanto a la localización de los campings en Galicia (ver Mapa 4), en un primer momento se percibe cierta similitud con la localización de las casas de turismo rural. 


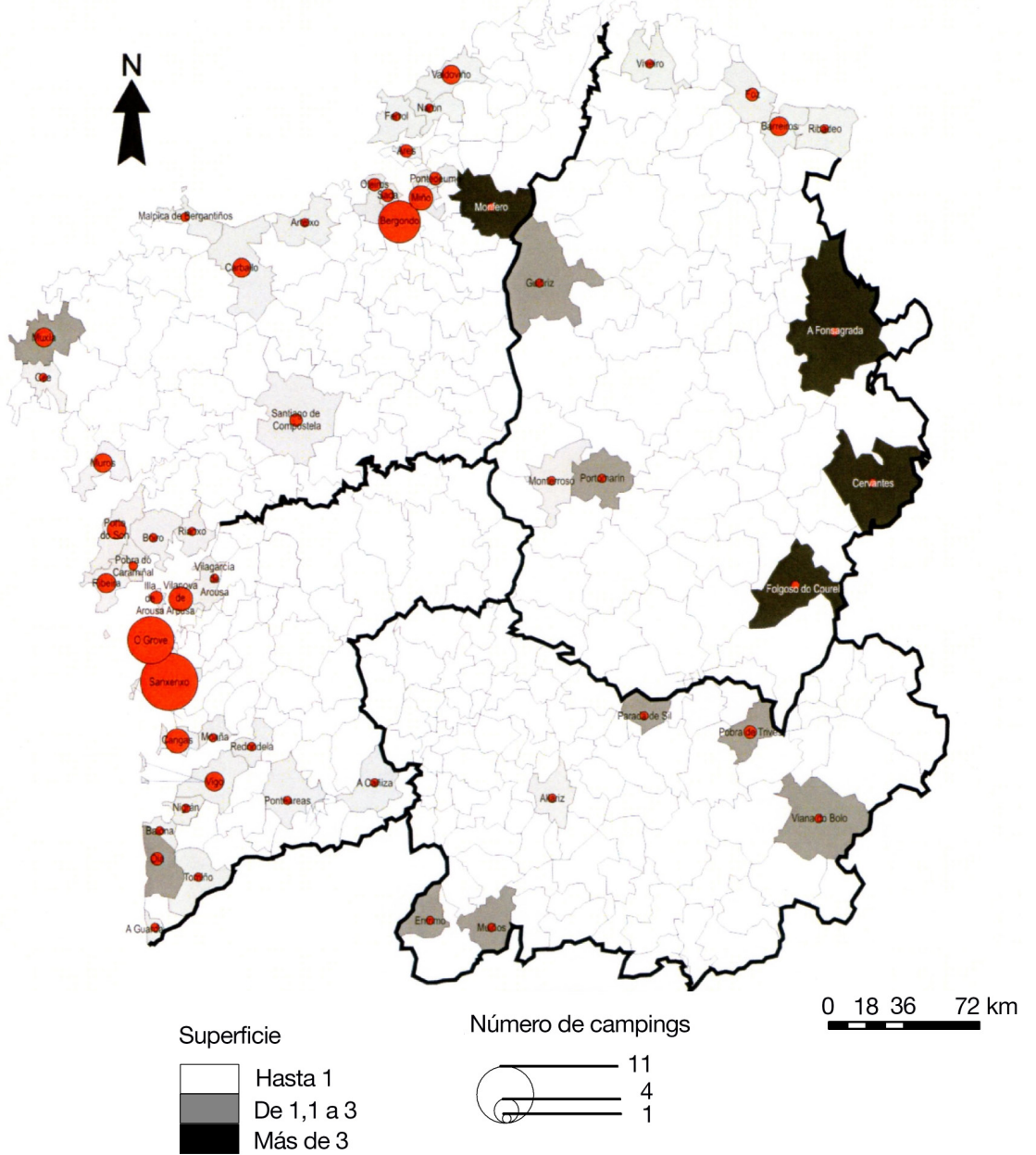

Mapa 4. Localización de los campings y la superficie forestal arbórea (ha) por habitante a escala municipal en Galicia.

Fuente: elaboración propia a partir de datos del Cuarto Inventario Forestal Nacional: Galicia. MAGRAMA (2011) y Campings 2014, Xunta de Galicia (2014).

Su distribución territorial es muy heterogénea, pues hay campings en áreas urbanas, rurales, espacios con diversidad socioeconómica, etc. Algo similar ocurre con su emplazamiento desde el punto de vista turístico, pero si cabe en mayor medida en los campings que en las casas de turismo rural. Pues las áreas gallegas que destacan por su actividad turística de sol y playa son el destino mayoritario de los campings (la comarca do Barbanza, Sanxenxo, Ogrove o el área da Coruña). Mientras que en las áreas rurales e interiores de Galicia y, 
especialmente, en las que tienen representatividad dentro de las superficies de masas arbóreas, la oferta de campings se puede definir como anecdótica.

En consecuencia, se debe potenciar este tipo de alojamientos turísticos que permitan aprovechar y dinamizar los usos y valores recreativos de los montes gallegos. Pero insistiendo en una ordenación territorial de los mismos, en la que se favorezca la implantación de nuevos campings en las áreas que posean una serie de recursos naturales que puedan ofrecerse como una oferta complementaria al alojamiento. Así se conseguiría, por un lado, que estas dotaciones sean más atractivas para los turistas y, por otro, se favorecerían actividades como el turismo forestal. Otro aspecto en el que también hay que incidir es en las características que deben tener estos alojamientos, pues existen diversos ejemplos que con la pretensión de «ofertar nuevas actividades» $\mathrm{y}$ «diversificar los servicios» lo único que han conseguido ha sido el efecto contrario: alterar el medio natural y la sociedad de ese territorio (sirva de ejemplo el área de la provincia de Pontevedra, Sanxenxo-Portonovo). Por este motivo, hay que prestar atención a las infraestructuras que se realizan en los campings, el personal que se emplea, los materiales que se utilizan en las edificaciones, etc.

\subsection{El monte, las áreas recreativas y los miradores}

Como se viene exponiendo, desde una perspectiva amplia el ecoturismo se puede definir como aquellas actividades turísticas que se basan en la naturaleza, en las que los visitantes viajan a ciertos territorios con la pretensión de apreciar su riqueza natural. Así, dentro de esta visión general del ecoturismo se encuentra el turismo forestal (paseo, percepción o visión de los montes) como una actividad recreativa dentro del ecoturismo por lo que la distribución y localización de una serie de áreas recreativas y miradores bien acondicionados permitirían el desarrollo y el aprovechamiento de los usos y valores turísticos de los montes gallegos.

Una vez más, al observar la localización territorial de las áreas recreativas y los miradores de Galicia (ver Mapa 5), se comprueba que gran parte de los municipios gallegos tienen alguna de estas dotaciones. De nuevo, pues, y dadas las características territoriales, se comprueba que la oferta de poder observar paisajes o de estar en contacto con la naturaleza es heterogénea.

De todos modos, aunque en menor medida que en las variables anteriormente expuestas, la mayoría de estas áreas recreativas se asientan en municipios que destacan por diversas características como el hecho de ser litorales - de playa o de desembocadura o tramos de cursos fluviales-, pero no por sus masas arbóreas. Por ejemplo, a lo largo de las Sierras Orientales de Galicia, que es donde se encuentran las mayores superficies de montes que mantienen unos importantes valores naturales, el número de áreas de recreo y miradores es mucho menor que en otras áreas como la comarca do Barbanza o el sur de la provincia de Pontevedra.

Por lo tanto, la creación de una red de áreas recreativas y miradores sería una herramienta muy importante para dinamizar los usos y los valores turísti- 


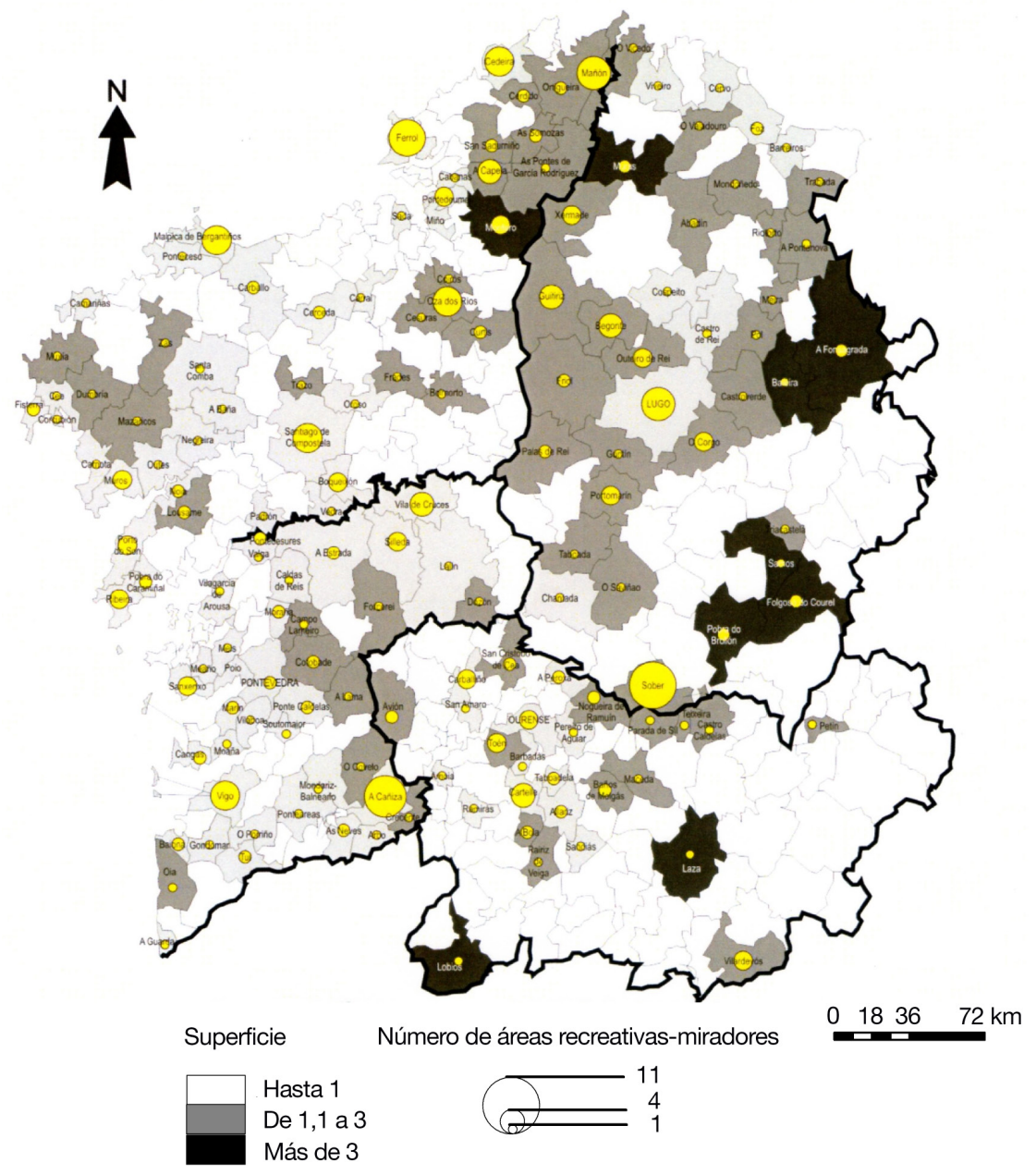

Mapa 5. Localización de las áreas recreativas-miradores y la superficie forestal arbórea (ha) por habitante a escala municipal en Galicia.

Fuente: elaboración propia a partir de datos del Cuarto Inventario Forestal Nacional: Galicia. MAGRAMA (2011) y «Áreas de recreo e miradoiros» consulta en <www.turgalicia.es>. Xunta de Galicia (2014).

cos del monte de Galicia. Conviene destacar que, aunque este tipo de dotaciones suelen ser destino de turistas que realizan una visita que no va más allá de la realización de un picnic o una ruta, con un tiempo de estancia que no supera un día, su repercusión para el desarrollo del turismo forestal es muy elevado, ya que esta área tiene que estar controlada periódicamente y "protege» estos suelos de otros posibles usos que no dinamizan social ni económicamente este territorio. 


\subsection{El monte y los centros de educación ambiental}

La educación ambiental es una de las actuaciones que, por una parte, ayuda a luchar contra la crisis que existe entre la sociedad actual y la naturaleza, y que por otra parte muestra los usos y los valores turísticos del medio natural, y por lo tanto, de los montes. Como expone Serantes (2005), en el intento de mejorar las relaciones que las personas mantenemos con la naturaleza, la educación ambiental partió de postulados positivistas y científicos, para pasar progresivamente a posturas más críticas y con un mayor compromiso ético.

Dentro de las diferentes concepciones de la educación ambiental se decidió crear una serie de recursos que facilitasen la comprensión de la complejidad teórica del problema, que promoviesen respuestas interdisciplinarias, que permitiesen la participación y el compromiso de las personas en la mejora del medio natural, y que propiciasen la coordinación entre diferentes agentes para la optimización de los esfuerzos.

Así, los instrumentos según el Libro Blanco de la Educación Ambiental en España (Ministerio de Medio Ambiente, 1999) deben basarse en el aprendizaje social, en la responsabilidad, la participación y la experimentación. La educación ambiental tiene que facilitar la adquisición de conocimientos, de actitudes y de habilidades, así como sensibilizar y concienciar a las personas para que participen en la resolución de los problemas ambientales.

Por lo tanto, la puesta en valor y en conocimiento de los usos turísticos de los montes gallegos de un modo coherente y ordenado se antoja como una de las actuaciones que se deben incluir en gran parte de los módulos, cursos y ciclos de la educación ambiental.

Dentro de la tipología de los centros en los que se imparte educación ambiental: centros de visitantes, aulas de la naturaleza, granjas-escuela, museos y zoos, se considera que la idónea para el desarrollo y la exposición de los valores turísticos del monte gallego son las aulas de la naturaleza, ya que se proponen como una estrategia de aprendizaje, actividades, talleres y rutas a cargo de profesionales. Su metodología de trabajo suele buscar un modo directo de participación e implicación tanto de los visitantes como de la población local.

De los 116 centros que se recogen en la Guía dos Equipamentos para a Educación Ambiental na Galiza el 30\% son aulas de la naturaleza, tipología que solo se ve superada por los centros de visitantes (Serantes, 2005). La mayoría de estos centros se localiza en las áreas urbanas de Galicia, tanto en las ciudades como A Coruña, Vigo o Ferrol, o en las villas como O Carballiño, A Estrada o Cambados (ver Mapa 6).

En un primer momento esta localización puede resultar coherente según valores sociales y demográficos pues en estas áreas es donde se concentran los mayores valores de población y, por lo tanto, la utilización de estos centros está más asegurada. Con todo, se considera que la construcción de estos centros en áreas rurales es el lugar idóneo para la exposición de las potencialidades y las utilidades del medio natural, así como de los montes desde el punto medioambiental y turístico. 


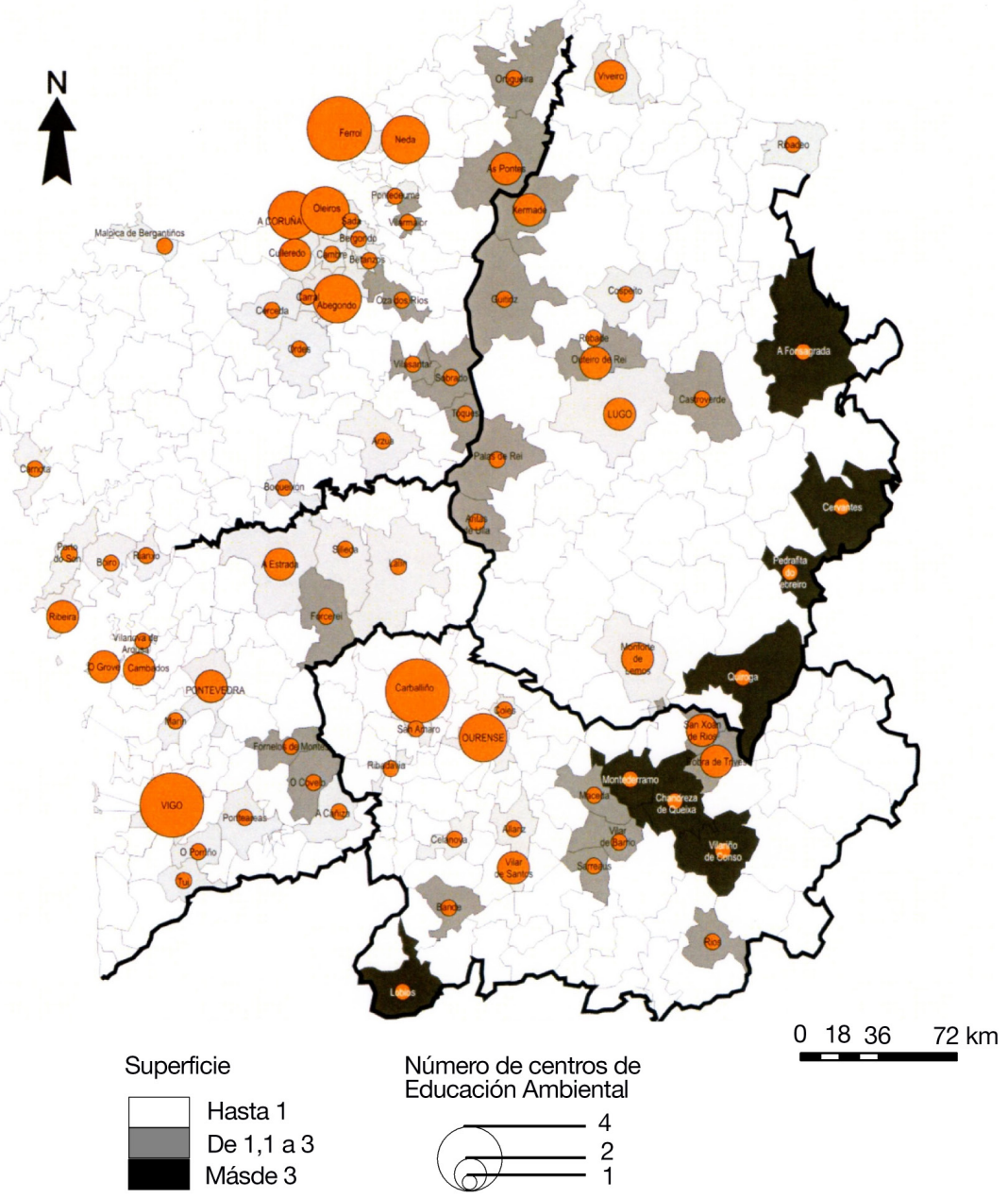

Mapa 6. Localización de Centros de Educación Ambiental y la superficie forestal arbórea (ha) por habitante a escala municipal en Galicia.

Fuente: elaboración propia a partir de datos del Cuarto Inventario Forestal Nacional: Galicia. MAGRAMA (2011) y Guía dos Equipamentos para a Educación Ambiental na Galiza (Serantes, 2005).

\subsection{El monte y sus producciones secundarias}

Antes de concluir este apartado hay que recordar que los montes gallegos tienen la función principal de producir madera, especialmente de coníferas y eucaliptos. Con todo, existen otro tipo de actividades, compatibles en la mayoría de los casos con la producción maderera, que cada vez tienen mayor significación 
y que guardan una relación muy directa con el turismo forestal, como son las denominadas "producciones secundarias del monte».

Dentro de las mismas destacan la caza, el aprovechamiento de setas, los frutos comestibles como la castaña o las moras y las plantas aromáticas. Todas estas producciones representan un ejemplo de rendimientos sostenibles, perfectamente compatibles con la producción maderera, que pueden proporcionar beneficios a la población local y que son muy bien valorados por la sociedad actual. Además, constituyen una actividad compatible y complementaria del turismo forestal, y que muestra los usos y los valores turístico-recreativos que pueden tener los montes de Galicia.

Desde hace unos años cobró importancia el sector denominado «pequeños frutos forestales» que engloba moras, arándanos, endrinas y grosellas. Los principales demandantes de estos productos son las fábricas de mermeladas, chocolates, licores y productos lácteos, aunque cada día aumenta más la venta de los mismos por comerciantes minoristas. Está más que comprobado que la búsqueda, la recolección y la transformación de estos productos es una actividad demandada y muy del gusto de los turistas naturales, del turismo forestal, por lo que su promoción además de ser un recurso para la dinamización de este tipo de turismo, expresa la potencialidad de los montes. Estamos ante un nuevo elemento de desarrollo y de atractivo sostenible de las áreas rurales de Galicia. Además, la puesta en funcionamiento de esta actividad se podría potenciar de un modo muy factible, por ejemplo como complementaria dentro del turismo rural con la implantación de una serie de rutas y talleres en los que se manipulasen estos productos.

Otro producto que manifiesta la productividad y el valor turístico del monte gallego son las castañas. Desde la antigüedad, la castaña, fue uno de los aprovechamientos más importantes y conocidos de los montes gallegos, pues hasta la llegada de la patata fue el sustento alimenticio básico tanto de la población como de la ganadería de ciertos territorios. En la actualidad, Galicia es el principal productor de este fruto de España, a pesar de las diferentes pestes y plagas que sufrieron los castaños a lo largo de la historia y de la nula significación que tuvo dentro de los planes de repoblación forestal.

Actualmente, de los montes gallegos se están extrayendo toneladas de plantas aromáticas y medicinales. La recolección de estas plantas que se reproducen mayoritariamente de un modo natural y salvaje podría ofrecer mayores beneficios si se ordenase tanto su plantación como su extracción, y se enfocasen ciertas fases de esta actividad hacia la puesta en valor del monte desde el punto de vista turístico.

Otra actividad que muestra el valor turístico de los montes y que posee una amplia demanda es la caza. Con todo, lo que se considera fundamental para su correcto funcionamiento es que debe estar organizada, debe existir iniciativa empresarial y se debe acondicionar una superficie de monte suficiente para el desarrollo de la misma. Además existen determinadas áreas forestales que poseen características de relieve, orografía, vegetación, etc., que limitan mucho su utilización para otros usos como la obtención de madera o productos secun- 
darios que sí podrían ser muy válidos para la creación de diferentes cotos de caza, en los que lo ideal sería la implicación de diferentes propietarios forestales.

En último lugar, se puede destacar el valor turístico que tiene una actividad agraria que se realiza en Galicia desde hace más de veinte años como es la recolección de setas.

Una serie de personas de Galicia como de otros lugares de España, atraídos por las magníficas condiciones climáticas y edafológicas de los montes gallegos comenzaron a recolectar y transformar estos productos (frescos, congelados o secos). Esto favoreció la explotación de algunas especies como el Boletus o el Lactarius que se exportan a Cataluña, Francia, Alemania o Italia. Así pues, ofertar estos productos desde el punto de vista turístico parece una iniciativa que tiene garantizado su éxito.

\section{Conclusiones}

Los resultados del estudio que se presenta han sido, tan solo, un primer paso que exige mucha más investigación sobre las multifuncionalidades de los montes gallegos y, entre ellas, especialmente el turismo.

Además, con el paso de las décadas, el turismo se ha convertido en una actividad en expansión que es demandada por un mayor número de personas y en la que los montes y los árboles constituyen un elemento y un espacio óptimo para que la población pueda satisfacer sus necesidades y deseos de naturaleza.

Una de las reflexiones que se puede extraer de este trabajo es que se debe realizar un exhaustivo trabajo de planificación de la función recreativa y turística sobre el territorio, y más cuando se está hablando de dinamizar el turismo forestal, pues los niveles de frecuentación de los montes se pueden convertir en uno de sus mayores problemas motivados por la posibilidad de degradar las potencialidades naturales y de disfrute de estos territorios.

Por lo tanto, la creación de una red de espacios forestales con una serie de infraestructuras coherentes según las características territoriales, debería ser una opción muy a tener en cuenta para el desarrollo del turismo en Galicia. Además dentro de esta red se podría realizar una pequeña diferenciación tipológica de los montes, lo que permitiría una redistribución territorial de la actividad turística en los espacios forestales y una posible reducción de los impactos.

En un grupo estarían los montes urbanos o elementos turísticos como los árboles monumentales. Otro grupo lo englobarían los montes que se encuentran próximos a las ciudades, que se podrían denominar montes periurbanos, que se caracterizarían por su atractivo paisajístico pero con un índice de fragilidad bastante pequeño.

Los montes a escala comarcal configurarían otro grupo que, quizás, tendría un valor más como elemento de desarrollo local, una vinculación más directa entre la actividad turística y la mejora de la estructura socioeconómica de estas comarcas.

La sociedad gallega sabe que Galicia tiene unas magníficas condiciones para que el turismo se desarrolle y alcance mayor importancia dentro de la 
estructura socioeconómica, pero en la actualidad pese a esta gran potencialidad conocida existen una serie de carencias que impiden la consolidación esperada.

Uno de los mayores problemas es el de la estacionalidad, pues los turistas que visitan Galicia se concentran en los meses de verano, lo que afecta negativamente a todo el sector, pues impide la mejora de la calidad y los márgenes de rentabilidad con lo cual se limitan sus posibilidades de crecimiento y actualización al mercado. Por lo tanto, el aprovechamiento de los recursos naturales y culturales es necesario para la diversificación del producto turístico. De hecho, consideramos que el apoyo al desarrollo del turismo forestal puede ser bastante importante para el consumo del sector y de la economía en general.

Además, con la promoción del turismo forestal se ayudaría a conseguir la desestacionalización y el desarrollo de las comarcas gallegas de mayor carácter rural, que están padeciendo un agudo descenso de la población y estancamiento económico. Como se viene exponiendo, el turismo forestal se caracteriza por ser respetuoso con el medio natural, el patrimonio y las sociedades locales, aunque también es necesario preocuparse por evitar una saturación de estos territorios, lo que podría provocar el efecto contrario. Además, dadas las características del turismo forestal, también se debe aprovechar su perfecta capacidad de acoplamiento a otras actividades turísticas como el tradicional turismo de sol y playa o el turismo rural, con lo que además de aprovechar las áreas forestales se ayudaría a potenciar otros tipos de turismo. Cabe recordar que una de las mayores debilidades del turismo rural es la falta de una atractiva oferta de actividades complementarias, pues esta modalidad se centra de forma excesiva en la oferta de alojamientos.

En definitiva, con la promoción del turismo forestal no solo se reduciría la estacionalidad del turismo en Galicia y se crearía un nuevo elemento de atracción de un tipo de turistas escasos en el mercado gallego, sino que también se contribuiría a la dinamización de un número considerable de comarcas de carácter rural.

\section{Referencias bibliográficas}

Alonso, Juanjo (2000). Bosques con encanto. Madrid: El País Aguilar.

Anderson, Jon; Clément, Jean y Crowder, Loy Van (1998). "Conciliar los intereses contrapuestos en la actividad forestal: Nuevos conceptos en el marco del pluralismo». Conciliar la multiplicidad de intereses en la actividad forestal. FAO (Organización de las Naciones Unidas para la Agricultura y la Alimentación). Departamento de Montes. Revista Unasylva, 49 (194), 11.

ARAQUE, Eduardo (2005). «Las nuevas funciones recreativas de los montes. Reflexiones desde un escenario privilegiado: las Sierras de Segura y Cazorla (Jaén)». Cuadernos de Turismo, 15, 7-25.

Balboa, Jesús (1999). O monte en Galicia. Vigo: Xerais.

BARLOw, Katanya y Cocklin, Chris (2003). «Reconstructing rurality and community: plantation foresty in Victoria, Australia». Journal of Rural Studies, 19, 65-73.

Barroso, María de la O y Flores, David (2003). «Bases para la elaboración de un Plan de desarrollo turístico sostenible en el Parque Natural Sierra de Aracena y 
Picos de Aroche». Congreso Internacional Territorios, Cooperación y Desarrollo Sostenible. Cáceres, Universidad de Extremadura, 10.

Besteiro, Begoña (1997). "Análisis estructural de los problemas del turismo en Galicia: balance de una década (1991-2001)». Cuadernos de Traballo do IDEGA (Instituto de Estudos e Desenvolvemento de Galicia). Economía Aplicada, 14. USC (Universidade de Santiago de Compostela), 44.

Blanco, Ricardo y Benayas, Javier (1994). «El turismo como motor del desarrollo rural». Revista de Estudios Agrosociales, 169, 119-147.

Bori-Sanz, Mónica y Niskanen, Anssi (2002). Nature-based tourism in forests as a tool for rural development-Analysis of three study areas in North Karelia (Finland), Scotland and the Catalan Pyrenees. Joensuu (Finlandia): EFI (European Forest Institute).

Bourdu, Robert (1988). Arbres souverains, París: Du May.

Bounier, Abel (1979). La Galice. Essai geographique d'analyse et d'interprétation d'un vieux complexe agrarie. II tomos, La Roche-Sur-Yon.

- (1984). «Las formas tradicionales de utilización del monte, su evolución reciente, las perspectivas de porvenir». Cuadernos de Área de Ciencias Agrarias. Seminario de Estudos Galegos, 5, 11-28.

Buendía, José Daniel y Colino, José (eds.) (2001). Turismo y medio ambiente. Murcia: Cámara de Murcia y Civitas Economía y Empresa.

Cals, Joan, Capellà, Josep y Vaque, Empar (1995). El turismo en el desarrollo rural de España. Madrid: Ministerio de Agricultura Pesca y Alimentación.

Calvo, José Luis et al. (2003). «Las características turísticas como motor de desarrollo rural en los espacios protegidos: el caso de la Sierra de Gúdar (Teruel)». La Geografía y la Gestión del Turismo. Actas del VIII Coloquio de Geografía del Turismo, Ocio y recreación, Santiago de Compostela, 173-183.

CÁnoves, Gemma et al. (2003). "Los turistas del turismo rural. Análisis de los casos de Cataluña, Galicia y Baleares». La Geografía y la Gestión del Turismo. Actas del VIII Coloquio de Geografía del Turismo, Ocio y recreación, Santiago de Compostela, 185-199.

Donaire, José Antonio y Gordi, Josep (2003). "Bosque y Turismo». Boletín de la Asociación de Geógrafos Españoles, 35, 207-221.

ExCELTur (2011). Estudio IMPACTUR Galicia 2010. Madrid: Exceltur (Alianza para la Excelencia Turística).

Fernández, Xoaquín (1990). Economía (política) do monte galego. Santiago de Compostela: Servicio de Publicacións e Intercambio Científico da Universidade de Santiago de Compostela.

Fernández-Cavada, José Luis y Ortuño, Sigfredo (1999). Desarrollo rural y sector forestal. Madrid: E. T. S. Ingenieros de Montes.

Font, Xavier y Tribe, John (eds.) (2000). Forest Tourism and Recreation. Cases Studies in Environnmental Mangement. High Wycombre, UK: CABI Plubishing, Buckinghamshire Chilterns University College.

Gómez-Limón, Javier y De Lucio, José Vicente (1995). «Uso de las áreas recreativas en espacios naturales de entornos metropolitanos». II Simposium sobre espacios naturales en áreas metropolitanas y periurbanas, Barcelona: FEDENATUR (Asociación Europea de Parques Periurbanos).

Gómez, Josefina y MATA, Rafael (2006). «Paisajes forestales españoles y sostenibilidad. Tópicos y realidades». AREAS Revista Internacional de Ciencias Sociales, 25, La transformación del territorio, antes y después de 1950, Universidad de Murcia, 13-29. 
Gordi, Josep (2000). Passejades pels boscos de Catalunya. Barcelona: Pòrtic, 127.

Grundy, Isla y Le Breton, Gus (1997). «El Programa SAFIRE MITI- un Nuevo Enfoque al Manejo de los Recursos Naturales en Zonas Comunales de Zimbabwe». Red Forestal para el Desarrollo Rural. Documento de la Red 22e, 16-29.

Hermanin, Luigi et al. (1988). "La funzione turistico-ricreativa nell'assestamento dei boschi trentini». Annali dell'Accademia Italiana di Scienze Forestali, 37, 409-430.

Lage, Jesús Adolfo (2003). Bosques, sociedad y cultura forestal en Galicia. Vigo: Servizo de Publicacións da Universidade de Vigo.

Langoya, Dickson y Long, Catherine (1997). "Las Comunidades Locales y el Desarrollo del Ecoturismo en la Reserva Forestal de Bugondo, Uganda». Red Forestal para el Desarrollo Rural. Documento de la Red 22e, Londres, 1-16.

LESLEI, Rod (2003). «Los espacios forestales recreativos tienen un precio». Rentabilizar los bosques. FAO (Organización de las Naciones Unidas para la Agricultura y la Alimentación). Departamento de Montes. Revista Unasylva, 212, 11.

Ministerio de Medio Ambiente y Medio Rural y Marino (2011). IV Inventario Forestal Nacional: Galicia. A Coruña, Lugo, Ourense y Pontevedra. Varios tomos. Madrid.

Ministerio de Industria, Turismo y Comercio (2004). El turismo de naturaleza en España y su plan de impulso. Estudios de productos turísticos. Madrid.

Ministerio de Medio Ambiente (1999). Estrategia Forestal Española. Madrid: Dirección General de Conservación de la Naturaleza.

Ministerio de Medio Ambiente (1999). Libro Blanco de la Educación Ambiental en España. Madrid: Secretaría General de Medio Ambiente.

Ministerio de Medio Ambiente (2002). Plan Forestal Español (2002-2032). Madrid: Dirección General de Conservación de la Naturaleza.

Miramontes, Ángel (2010). La industria de la madera en Galicia. La significación del subsector del mueble. Santiago de Compostela: Servicio de Publicaciones de la Universidade de Santiago de Compostela.

Montiel, Cristina (2003). «El turismo de interior en el desarrollo socioeconómico de las comarcas forestales de la Comunidad Valenciana». Investigaciones geográficas, 31, Instituto Universitario de Geografía, Universidad de Alicante, 15-36.

- (2003). «Tradición, renovación e innovación en los usos y aprovechamientos en las áreas rurales de montañas». Cuadernos Geográficos, Universidad de Granada, 7-26.

Nogué, Joan. (1986). La percepció del bosc. Girona: Diputació de Girona i Ajuntament d'Olot (Col-lecció Josep Pla, 172).

Ortega, José (2004). «Áreas de montaña: de la supervivencia a la integración». Boletín de la Asociación de Geógrafos Españoles, 38, 5-28.

Ortuño, Sigfredo (2000). «La transformación del mundo rural en España». Revista Forestal Española, 25, 4-11.

Pérez, María Mar y López, Edelmiro (2005). «La contribución del turismo a la diversificación de actividades en un espacio rural periférico. Análisis del impacto de la Iniciativa LEADER en Galicia». Revista de Estudios Agrosociales y Pesqueros, 206. Madrid: Ministerio de Agricultura, 111-135.

Plaisance, Georges (1997). Guide des forêts de France. París: Pierre Horay Editeur.

Prada, Albino (1991). Montes e Industria. O Circuito da Madeira en Galicia. Serie de Estudios Sectoriales. Vigo: Fundación Caixa Galicia.

Regueiro, Miguel (1994). Ecoturismo. Nuevas formas de turismo en el espacio rural. Barcelona: Colección Bosch Turismo. 
RodríGuez, Carlos e Izco, Jesús (2003). Arboles monumentales en el patrimonio cultural de Galicia. II volúmenes. Santiago de Compostela: Consellería de Cultura, Comunicación Social e Turismo, Xunta de Galicia.

Rodríguez, Antonio (2004). Usos e funcións do Bosque. Colección técnica medio ambiente. Santiago de Compostela: Consellería de Medio Ambiente, Xunta de Galicia.

Rodríguez, Gonzalo y Martinez, Fidel (2009). Nuevos retos para el turismo. A Coruña: Netbiblo.

Roquero, Luisa (1999). El sacro bosco de Bomarzo. Madrid: Eceleste Ediciones.

RuIz, Pedro (1995). «Perspectivas y nuevas orientaciones del turismo rural». En: Hacia un nuevo sistema rural. Serie Estudios, 99, MAPA, Secretaría General Técnica.

Serantes, Araceli (2005). Guía dos equipamentos para a Educación Ambiental na Galiza e doutras instalacións para a divulgación do Patrimonio. Documentos para a Educación Ambiental do CEIDA (Centro de Extensión Universitaria e Divulgación Ambiental de Galicia), 1. A Coruña.

Susmel, Lucio (1968). «La terza dimensione della foresta». Annali Accademia Italiana di Scienze Forestali, volumen XVII, 17-34.

Terluin, Ida (2003). «Differences in economic development in rural regions of avanced countries: An overview and critical análisis of theories». Journal of Rural Studies, 19, 327-344.

Theophile, Karin (1996). «Los bosques y el empleo». FAO (Organización de las Naciones Unidas para la Agricultura y la Alimentación). Departamento de Montes. Revista Unasylva, 47, 52-57.

Valenzuela, Manuel (1984). «El uso recreativo de los espacios naturales de calidad (Una reflexión sobre el caso español)». Estudios Turísticos, 82, 3-15.

Van Pelt, Robert (2001). Forest giants of the pacific coast. Vancouver: Global Forest Society.

VINYETA, Ramon (1995). Els arbres monumentals de Catalunya. Torelló: Celblau.

Vega, Fernando (coord.) (1997). Análisis territorial del turismo: una nueva geografía del turismo. Barcelona: Ariel Geografía.

Xunta de Galicia (2001). O Monte Galego en Cifras. Santiago de Compostela: Consellería de Medio Ambiente, Dirección Xeral de Montes e Medio Ambiente Natural, 226.

Xunta de Galicia (2014). Plan Integral de Turismo de Galicia 2014-2016. Santiago de Compostela: Agencia Turismo de Galicia.

Xunta de Galicia (2014). Turismo Rural 2014. Turismo de Galicia. Santiago de Compostela, 124 (consulta en <www.turgalicia.es>, marzo de 2014).

Xunta de Galicia (2014). Campings 2014. Turismo de Galicia. Santiago de Compostela, 40 (consulta en <www.turgalicia.es> marzo de 2014).

Xunta de Galicia (2014). Áreas de recreo e miradoiros. Turismo de Galicia. Santiago de Compostela (consulta en <www.turgalicia.es> marzo 2014). 